\title{
HUBUNGAN MATAKULIAH TATA RIAS DAN BUSANA DENGAN JASA MUA PADA LULUSANDAN MAHASISWA PRODI PENDIDIKAN TARI UNIVERSITAS NEGERI MEDAN
}

\author{
Malisa Binti Ali Ibrahim ${ }^{1}$, Sitti Rahmah ${ }^{2}$ \\ Program Studi Pendidikan Tari, Fakultas Bahasa dan Seni,Universitas Negeri Medan \\ Jalan Willem Iskandar Pasar V Medan Estate 20221, Sumatera Utara-Indonesia \\ Email: ${ }^{1}$ malisaibrahim11563@gmail.com, ${ }^{2}$ srahmaiyen@yahoo.com
}

\begin{abstract}
This study aims to understand the positive relationship between cosmetology and fashion courses with entrepreneurial Make Up Artist services for graduates and students of Medan State University Dance Education. The theoretical foundation in this paper is used as a guideline in writing a thesis consisting of cosmetology theory (Harymawan, 1993: 134), namely makeup is the art of using cosmetic materials to provide makeup or changes to the players on stage or stage with the appropriate atmosphere and naturally, the fashion code of Endang Caturwati (1996: 36), what is meant by clothing is everything that a person wears, consisting of clothing and accessories (accessories) and identical to the word costume, and entrepreneurial theory Thomas W. Zimmerer in Suryana (2011: 19) states entrepreneurship is the process of applying creativity and innovation in solving problems and finding opportunities to improve life or business. This research was conducted in November to January 2017. The data obtained were analyzed using quantitative data analysis using the Product Moment Correlation formula. The location of the study was conducted in the Dance Education Study Program at the Language and Arts Faculty of Sendratasik, Medan State University, Jl. Williem Iskandar Pasar V Medan Estate. Based on the results of the research conducted, it can be seen that cosmetology and fashion subjects make an effective contribution of $80.7 \%$ towards entrepreneurship for Make Up Artist services, it can be seen that the cosmetology courses really pay attention to the shape of the face with the desired makeup as well as the fashion where the subject provides knowledge about the differences in traditional clothing and creative clothing, so graduates and students are motivated to apply and hone the ability to become a make up artist service.
\end{abstract}

Keywords: Makeup and Clothing, Make Up Artist Entrepreneurship Services.

\begin{abstract}
ABSTRAK
Penelitian ini bertujuan mengetaui hubungan positif antara matakuliah tata rias dan busana dengan kewirausahaan jasa Make Up Artist pada lulusan dan mahasiswa Pendidikan Tari Universitas Negeri Medan. Landasan teoritis dalam skripsi ini dijadikan pedoman dalam penulisan skripsi yang terdiri dari teori tata rias (Harymawan,1993:134) yaitu Tata rias adalah seni menggunakan bahan-bahan kosmetika untuk memberikan dandanan atau perubahan pada para pemain di atas panggung atau pentas dengan suasana yang sesuai dan wajar, tata busana Endang Caturwati (1996:36), yang dimaksud dengan busana adalah segala yang dikenakan seseorang, yang terdiri dari pakaian dan perlengkapannya (accessories) dan identik dengan kata kostum, dan teori kewirausahaan Thomas W. Zimmerer dalam Suryana (2011:19) menyatakan kewirausahaan adalah proses penerapan kreativitas dan inovasi dalam memecahkan persoalan dan menemukan peluang untuk memperbaiki kehidupan atau usaha. Penelitian ini dilaksanakan pada bulan Nopember sampai dengan Januari 2017. Data yang diperoleh dianalisis menggunakan analisis data kuantitatif dengan menggunakan rumus Korelasi Product Moment Lokasi penelitian dilakukan di Prodi Pendidikan Tari Jurusan Sendratasik Fakultas Bahasa dan Seni Universitas Negeri Medan, Jl. Williem Iskandar Pasar V Medan Estate. Berdasarkan hasil penelitian yang dilakukan dapat diketahui bahwa matakuliah tata rias dan busana memberi sumbangan efektif sebesar 80,7\% terhadap kewirausahaab jasa Make Up Artist, hal ini dapat dilihat
\end{abstract}


bahwa matakuliah tata rias benar-benar memperhatikan bentuk wajah dengan dengan rias yang diinginkan begitu juga dengan tata busana yang mana matakuliah tersebut memberikan pengetahuan tentang perbedaan busana adat dan busana kreasi, sehingga lulusan dan mahasiswa termotivasi untuk mengaplikasikan dan mengasah kemampuan untuk menjadi seorang make up artist.

\section{Kata kunci : Tata Rias dan Busana, Kewirausahaan Jasa Make Up Artist.}

\section{PENDAHULUAN}

Pada saat ini masyarakat Indonesia merasakan sulitnya mencari pekerjaan. Kesulitan mencari pekerjaan tidak hanya dirasakan oleh masyarakat umum, tetapi juga dirasakan oleh para lulusan Perguruan Tinggi di Indonesia. Kondisi ini semakin diperparah dengan persaingan dunia kerja dengan lulusan Perguruan Tinggi yang mencapai 2,5 juta lulusan pertahunnya (Hendro, 2011:12). Pengangguran terjadi karena perbandingan antara jumlah penawaran kesempatan kerja tidak sebanding dengan jumlah lulusan atau penawaran tenaga kerja baru yang dihasilkan Perguruan Tinggi (Leonardus Saiman, 2012:22).

Menurut Leonardus Saiman (2012:22). Kesenjangan antara permintaan dan penawaran tenaga kerja ini perlu dipikirkan oleh kita semua, lebih-lebih tenaga kerja yang tidak terdidik, tidak terampil, atau tenaga kerja berpendidikan rendah, bila tidak tertampung di lapangan kerja formal, maka jalan satu-satunya adalah dibekali dengan keterampilan berwirausaha agar mereka setelah lulus sekolah/kuliah maupun berhenti sekolah/kuliah ditengah jalan tetap memperoleh penghasilan dan pada akhirnya mencapai kesejahterahan yang diharapkan, tanpa harus mengandalkan untuk menjadi pegawai/karyawan disuatu perusahaan.

Karena sulitnya mencari pekerjaan pada saat ini maka semakin banyaklah jumlah pengangguran di Indonesia. Pengangguran menjadi masalah serius yang masih sulit diatasi. Program pemerintah untuk mengurangi pengangguran belum mampu mengurangi pengangguran secara signifikan. Penyebabnya karena jumlah penduduk yang besar dan pertumbuhan penduduk yang semakin meningkat, tidak disertai bertambahnya lapangan kerja.

Salah satu solusi yang ditempuh untuk mengatasi pengangguran di Indonesia adalah dengan menciptakan wirausaha. Dengan berwirausaha, akan membantu pemerintah dalam menciptakan lapangan pekerjaan baru. Dengan berwirausaha selain berpeluang menghasilkan pendapatan yang besar bagi wirausaha, juga mampu mengurangi jumlah pengangguran. Para wirausaha juga berkontribusi kepada perekonomian negara melalui pajak yang dihasilkan. Untuk mewujudkan tujuan tersebut, pemerintah dan masyarakat harus saling berkerjasama.

Untuk mewujudkan jiwa kewirausahaan dapat dimulai melalui pendidikan kewirausahaan yang diajarkan di Perguruan Tinggi, tetapi akan lebih cepat apabila pendidikan kewirausahaan juga mulai 
diterapkan dari keluarga, masyarakat dan lembaga pendidikan. Pada dasarnya pendidikan dapat dijadikan sebagai jembatan penghubung bagi manusia menuju kehidupan yang lebih baik. Pendidikan kewirausahaan diharapkan mampu membangkitkan semangat berwirausaha, berdikari, berkarya dan mengembangkan perekonomian nasional (Jamal Ma'mur Asmani: 2011). Pendidikan kewirausahaan juga diharapkan mampu memunculkan para wirausaha yang kreatif yang bisa menciptakan lapangan kerja dan bisa membantu mengurangi pengangguran yang tak pernah ada habisnya.

Pemerintah telah mencanangkan agar pendidikan kewirausahaan diterapkan di Perguruan Tinggi sebagai upaya menciptakan wirausaha-wirausaha muda berstatus sarjana yang berkompeten untuk ikut membantu pemerintah dalam mengurangi angka pengangguran. Pendidikan kewirausahaan diharapkan dapat memberikan bekal wawasan dan keahlian berwirausaha kepada mahasiswa saat lulus nanti.

Di Jurusan Sendratasik khususnya pada Prodi Pendidikan Tari Universitas Negeri Medansebagai salah satu lembaga pendidikan tinggi yang bergerak dibidang seni telah mempersiapkan lulusannya menjadi guru seni budaya (seni tari) khususnya. Namun disisi lain prodi pendidikan tari mencetak mahasiswa menjadi sarjana-sarjana yang terampil dalam bidangnya seperti mengelola sanggar tari, jasa penyewaan kostum tari, jasa make up wisuda, jasa dekorasi rias pengantin, maupun pengelola entertainment. Hal ini dapat dilihat dari kurikulum dan matakuliah yang berlaku diantaranya seperti matakuliah Tata Rias dan Busana.

Matakuliah tata rias dan busana adalah salah satu matakuliah bidang studi di Prodi Pendidikan Tari yang berbobot 3 sks dengan tim dosen pengampunya matakuliah tata rias Dr. Tuti Rahayu, Dra., M.Si dan tata busana adalahDra. Dilinar Adlin, M.Pd, matakuliah ini bertujuan untuk memberikan bekal kepada mahasiswa/i agar memiliki pengetahuan umum teoritis dan praktis tentang penataan wajah dan busana dalam kebutuhan pertunjukan tari.

Di dalam matakuliah tata rias dan busana mahasiswa mendapatkan wawasan pengetahuan teoritis maupun praktis, sehingga memperoleh bekal yang memadai setelah lulus. Implementasi dari pengetahuan ini dapat diterapkan di lapangan, bahkan sebelum lulus kuliahpun mahasiswa/mahasiswi seni tari bisa mencari uang tambahan untuk memenuhi biaya kuliah mereka sendiri dengan memanfaatkan keterampilan mereka masing-masing.

Berdasarkan penjelasan di atas, penulis berinisiatif melakukan penelitian mendalam untuk mengetahui apakah ada hubungan matakuliah tata rias dan busana dengan kewirausahaan mahasiswa dan alumni. Untuk itu judul dalam penelitian ini yaitu "Hubungan Matakuliah Tata Rias dan Busana dengan Kewirausahaan Jasa Make Up Artist pada Lulusan dan Mahasiswa Prodi Pendidikan Tari FBS Universitas Negeri Medan”. 
Adapun yang menjadi tujuan dalam penelitian ini adalah Adapun yang menjadi tujuan Mengetahui hubungan positif dan signifikan antara matakuliah tata rias (X1) dan tata busana (X2) dengan kewirausahaan jasa Make Up Artist (Y) pada lulusan dan mahasiswa Pendidikan Tari Universitas Negeri Medan.

Untuk membahas hubungan matakuliah tata rias dan busana dengan kewirausahaan jasa Make Up Artist, penulis menggunakan tiga teori oleh Harymawan tentang tata rias, oleh Endang Caturwati tentang kreativitas tata busana dan kewirausahaan oleh Thomas W. Zimmerer dalam Suryana.

Tata rias adalah seni menggunakan bahan-bahan kosmetika untuk mewujudkan wajah peranan dengan memberikan dandanan atau perubahan pada para pemain di atas panggung atau pentas dengan suasana yang sesuai dan wajar (Harymawan,1993:134), jika dikaitkan dengan matakuliah tata rias menurut pengalaman belajar penulis pada matakuliah tata rias dan busana yang diperoleh pada Prodi Pendidikan Tari Universitas Negeri Medan, proses belajar mengajar dilaksanakan dalam tatap muka sebanyak dua kali dalam satu minggu, satu pertemuan untuk materi tata rias dan satu pertemuan berikutnya untuk materi tata busana. Content (isi) dari proses belaar matakuliah tata rias dan busana ini adalah tata riasnya mempelajari beberapa riasan yaitu rias cantic, rias panggung, rias karakter (badut dan tengkorak), rias flora (bunga), rias fauna (kelinci, harimau, kera, ular), rias fancy atau biasa disebut fantasi nasional (face painting dan body painting),dan matakuliah tata rias mempelajari tentang bagaimaana pemasangan sanggul tradisi dan kreasi, sedangkan untuk tata busanya mempelajari bagaimana busana adat delapan etnis Sumatera Utara dan mengetahui bentuk busana tradisi dan kreasi pada siswa SMP dan SMA, lalu mendemonstrasikan busana yang sesuai dengan tata rias yang telah ditentukan oleh dosen matakuliah tata rias dan busana.

Tata busana dalam pengertian umum adalah pakaian lengkap yang dikenakan oleh seseorang untuk kebutuhan tertentu. Menurut Onong Nugraha dalam Endang Caturwati (1996). Jika dikaitkan dengan Materi matakuliah tata busana di Prodi pendidikan tari Universiatas Negeri Medan mempelajari tentang bagaimana busana adat delapan etnis Sumatera Utara dan mengetahui bentuk busana tradisi dan kreasi pada siswa SMP dan SMA, lalu mendemontrasikan busana yang sesuai dengan tata rias yang telah ditentukan oleh dosen matakuliah tata rias dan busana.

Fungsi busana adat yang dipergunakan adalah untuk suatu kegiatan adat yang diselenggarakan, seperti acara pernikahan ataupun pertunjukan busana adat pada suatu pagelaran, sedangkan untuk pembelajaran busana kreasi untuk sebuah pertunjukan tari adalah supaya mahasiswa/i dapat mengaplikasikan pemilihan warna busana, aksesoris, yang dipergunakan sesuai dengan kebutuhan pertunjukan tari. Dengan adanya pengetahuan dasar tentang tata busana bisa 
menjadi bekal pengetahuan mahasiswa/i dalam mendesain busana yang sesuai dengan keinginan, baik itu untuk busana tari busana pengantin dan juga busana yang digunakan untuk acara wisuda dan sebagainya. Dalam penelitian ini hanya difokuskan kepada busana tari dan juga busana yang dipergunakan untuk wisuda.

Thomas W. Zimmerer dalam Suryana(2011:19) menyatakan kewirausahaan adalah proses penerapan kreativitas dan inovasi dalam memecahkan persoalan dan menemukan peluang untuk memperbaiki kehidupan atau usaha. Kewirausahaan yang dimaksud dalam penelitian ini adalah kewirausahaan yang bergerak dibidang jasa yaitu kewirausahaan Jasa Make Up Artist yang ditekuni oleh lulusan dan mahasiswa prodi pendidikan tari Universitas Negeri Medan.

Tahapan selanjutnya penulis melaksanakan penelitian yang dilakukan di Lokasi penelitian di di Prodi Pendidikan Tari Jurusan Sendratasik Fakultas Bahasa dan Seni Universitas Negeri Medan, Jl. Williem Iskandar Pasar V Medan Estate 20221, Telp. (0 61) 6623942, Laman :http://fbs.unimed.ac.id, E mail: fbs@unimed.ac.id. Waktu penelitian ini dilaksanakan pada bulan Desember 2017 sampai April 2017.Populasi dan sampel dalam penelitian ini adalah mahasiswa yang telah mengikuti matakuliah tata rias dan busana dengan sampel sebanyak 20 orang. Tekhnik Pengumpulan Data yang dilakukan adalah sebagai dengan angket ,wawancara dan dokumentasi. Teknik pengolahan dan analisis data dalam penelitian ini dilakukan dengan uji statistik. Rumus yang digunakan adalah rumus teknik korelasi Product Moment dari Pearson. Kegunaan Product Momentadalah untuk melihat hubungan matakuliah tata rias dan busana dengan kewirausahaan jasa Make Up Artist.Ada beberapa persyaratan yang harus dipenuhi sebelum uji Product Moment dilakukan yaitu, uji normalitas, uji kecenderungan, uji prasyarat analisis, uji korelasi sederhana, uji korelasi ganda.

\section{HASIL DAN PEMBAHASAN}

Deskripsi Data Penelitian

Data yang telah disajikan dalam penelitian terdiri dari skor variabel Tata Rias (X1), Tata Busana (X2) dan Kewirausahaan Jasa make Up (Y). Deskripsi data yang ditampilkan menginformasikan skor tertinggi, skor terendah, rata-rata (mean), standar deviasi (SD), rentang skor (r), banyak kelas (k) dan panjang kelas (p) dan dilengkapi dengan tabel distribusi frekuensi dan grafik histogram variabel penelitian.

Dari data penelitian yang telah dilakukan menggunakan sebaran angket, diperoleh nilai tiap variabel sebagai berikut:

a. Tata Rias (X1)

Berdasarkan data variabel Tata Rias (X1) dari hasil penelitian yang diperoleh dengan jumlah responden 20 orang siswa terdapat skor tertinggi 62; skor terendah 19; dengan rata-rata $(\mathrm{M})=43,5$ dan standar deviasi $(\mathrm{SD})=14,31$ dengan rentang skor $(r)=43$; banyak kelas $(k)$ $=5$ dan panjang kelas $(\mathrm{p})=8$. Distribusi frekuensi data variabel Tata Rias (X1) dapat 
dilihat pada tabel dibawah dan perhitungan selengkapnya padapenelitian diperoleh nilai untuk:

$\mathrm{n}=20 \quad \sum \mathrm{X}=870$ $\sum X^{2}=41940$

a. Harga Rata-Rata Hitung / mean (M)

$$
\begin{aligned}
M & =\frac{\sum X}{n} \\
& =\frac{870}{20} \\
M & =43,5
\end{aligned}
$$

b. Standar Deviasi (SD)

$$
\begin{aligned}
\mathrm{SD} & =\frac{1}{\mathrm{~N}} \sqrt{\left(\mathrm{N} \cdot \sum \mathrm{X}^{2}\right)-\left(\sum \mathrm{X}\right)^{2}} \\
& =\frac{1}{20} \sqrt{(20.41940)-(870)^{2}}
\end{aligned}
$$

$=14,31$

c. Distribusi Frekuensi Data Integritas

Kepemimpinan

Berikut ini disajikan ringkasan

perhitungan distribusi skor variabel Variabel

Tata Rias (X1)

1) Rentang Skor (r)

$r=$ skor tertinggi - skor terendah

$=62-19$

$r=43$

2) Banyak Kelas Interval (k)

$\mathrm{k}=1+3,3 \log \mathrm{N}$

$=1+3,3 \log 20$

$=5,293$

$\mathrm{k}=5,293$ dibulatkan menjadi 5 kelas

3) Panjang Kelas Interval (p)

$$
\begin{gathered}
\mathrm{p}=\frac{43+1}{5} \\
\mathrm{p}=8,8 \text { dibulatkan menjadi } 8
\end{gathered}
$$

b. Tata Busana (X2)

Berdasarkan data variabel Tata Busana (X2) dari hasil penelitian yang diperoleh dengan jumlah responden 20 orang siswa terdapat skor tertinggi 62; skor terendah 19; dengan rata-rata $(\mathrm{M})=41,95$ dan standar deviasi $(\mathrm{SD})=13,43$ dengan rentang skor $(\mathrm{r})=$ 40 ; banyak kelas $(\mathrm{k})=5$ dan panjang kelas $(\mathrm{p})$ $=8$. Distribusi frekuensi data variabel Tata Busana (X2) dapat dilihat pada tabel dibawah dan perhitungan selengkapnya pada data penelitian diperoleh nilai untuk:

$$
\mathrm{n}=20 \quad \sum \mathrm{X}=839 \quad \sum \mathrm{X}^{2}=38801
$$

a. Harga Rata-Rata Hitung / mean (M)

$$
\begin{aligned}
M & =\frac{\sum X}{n} \\
& =\frac{839}{20} \\
M & =41,95
\end{aligned}
$$

b. Standar Deviasi (SD)

$$
\begin{aligned}
\mathrm{SD} & =\frac{1}{\mathrm{~N}} \sqrt{\left(\mathrm{N} \cdot \sum \mathrm{X}^{2}\right)-\left(\sum \mathrm{X}\right)^{2}} \\
& =\frac{1}{20} \sqrt{(20.38801)-(839)^{2}}
\end{aligned}
$$$$
=13,43
$$

c. Distribusi Frekuensi Data Integritas

Kepemimpinan

Berikut ini disajikan ringkasan

perhitungan distribusi skor variabel Variabel

Tata Busana (X2)

1) Rentang Skor (r)

$r=$ skor tertinggi - skor terendah 


$$
\begin{gathered}
=58-18 \\
r=40
\end{gathered}
$$

2) Banyak Kelas Interval (k)

$\mathrm{k}=1+3,3 \log \mathrm{N}$

$=1+3,3 \log 20$

$=5,293$

$\mathrm{k}=5,293$ dibulatkan menjadi 5 kelas

4) Panjang Kelas Interval (p)

$\mathrm{p}=\frac{40+1}{5}$

$\mathrm{p}=8,2$ dibulatkan menjadi 8

c. Kewirausahaan Jasa Make Up Artist

$$
\text { Berdasarkan data variabel }
$$

Kewirausahaan Jasa make Up Artist (Y) dari hasil penelitian yang diperoleh dengan jumlah responden 20 orang siswa terdapat skor tertinggi 62; skor terendah 19; dengan rata-rata $(\mathrm{M})=48,2$ dan standar deviasi $(\mathrm{SD})=14,60$ dengan rentang skor $(r)=44$; banyak kelas $(k)$ $=5$ dan panjang kelas $(\mathrm{p})=9$. Distribusi frekuensi data variabel Kewirausahaan Jasa make Up Artist (Y) dapat dilihat pada tabel dibawah dan perhitungan selengkapnya padadata penelitian diperoleh nilai untuk:

$\mathrm{n}=20 \quad \sum \mathrm{X}=963 \quad \sum \mathrm{X}^{2}=$ 50621

a. Harga Rata-Rata Hitung / mean (M)

$$
\begin{aligned}
M & =\frac{\sum X}{n} \\
& =\frac{963}{20} \\
M & =48,2
\end{aligned}
$$

b. Standar Deviasi (SD)

$$
\mathrm{SD}=\frac{1}{\mathrm{~N}} \sqrt{\left(\mathrm{N} \cdot \sum \mathrm{X}^{2}\right)-\left(\sum \mathrm{X}\right)^{2}}
$$

$$
=\frac{1}{20} \sqrt{(20.50621)-(963)^{2}}
$$

$=14,60$

c. Distribusi Frekuensi Data Integritas

Kepemimpinan

Berikut ini disajikan ringkasan

perhitungan distribusi skor variabel Variabel

Kewirausahaan Jasa make Up Artist (Y)

1) Rentang Skor (r)

$\mathrm{r}=$ skor tertinggi - skor terendah

$r=63-19$

$r=44$

2) Banyak Kelas Interval (k)

$\mathrm{k}=1+3,3 \log \mathrm{N}$

$=1+3,3 \log 20$

$=5,293$

$\mathrm{k}=5,293$ dibulatkan menjadi 5 kelas

3) Panjang Kelas Interval (p)

$$
\begin{aligned}
& \mathrm{p}=\frac{44+1}{5} \\
& \mathrm{p}=9
\end{aligned}
$$

1. Identifikasi Tingkat Kecenderungan Variabel Penelitian

a. Tingkat Kecenderungan Variabel Tata Rias (X1)

Dari hasil perhitungan tingkat kecenderungan variabel Tata Rias (X1) diperoleh skor rata-rata ideal (Mi) sebesar 40,5 dan skor standar deviasi ideal (SDi) sebesar 21,5., mempunyai tingkat Kecenderungan kategori cukup.

b. Tingkat Kecenderungan Variabel Tata Busana (X2) 
Dari hasil perhitungan tingkat kecenderungan variabel Tata Busana (X2) pada Lampiran 14 diperoleh skor rata-rata ideal (Mi) sebesar 38 dan skor standar deviasi ideal (SDi) sebesar 20. Mempunyai tingkat Kecenderungan kategori cukup.

C. Tingkat Kecenderungan Variabel Kewirausahaan Jasa make Up Artist (Y)

Dari hasil perhitungan tingkat kecenderungan variabel Kewirausahaan Jasa make Up Artist (Y) pada Lampiran 14 diperoleh skor rata-rata ideal (Mi) sebesar 41 dan skor standar deviasi ideal (SDi) sebesar 22. Mempunyai tingkat Kecenderungan kategori cukup.

1. Uji Prasyarat Penelitian

a. Uji Normalitas

Dari hasil pengujian dengan menggunakan SPSS, diperloleh hasil sebagai berikut Dari tabel hasil perhitungan diperoleh nilai $\mathrm{Z}$ untuk variabel matakuliah Tata rias $\left(\mathrm{X}_{1}\right)$, Tata busana $\left(\mathrm{X}_{2}\right)$ dan Kewirausahaan jasaMUA (Y) masing-masing 0,133 ; 0,188; dan 0,209 dengan nilai $\mathrm{p}>0,05$ (sig.2-tailed $>0,05$ ) jika dikorelasikan dengan nilai $\mathrm{Z} \leq 1,96$ artinya Variabel matakuliah Tata rias $\left(\mathrm{X}_{1}\right)$, Tata busana $\left(\mathrm{X}_{2}\right)$ dan Kewirausahaan jasaMUA berdistribusi normal.

b. Uji Linieritas

1) Variabel Tata rias $\left(X_{1}\right)$ dengan Kewirausahaan jasa MUA (Y) berdistribusi normal

Dari hasil pengujian dengan menggunakan SPSS, diperloleh hasil sebagai berikutpada $p$ linearity, diperoleh nilai $p$ sebesar 0,002 maka $\mathrm{p}<0,005$ dan nilai $\mathrm{p}$ pada deviation from linearity 0,234 maka $p>0,05$ yang artinya sebaran data adalah linear.

2) Variabel Tata Busana $\left(X_{2}\right)$ dengan Kewirausahaan jasaMUA (Y) berdistribusi normal.

Berdasarkan tabel perhitungan SPSS, pada $\mathrm{p}$ linearity, diperoleh nilai $\mathrm{p}$ sebesar 0,000 maka $\mathrm{p}<0,005$ dan nilai $\mathrm{p}$ pada deviation from linearity 0,238 maka $p>0,05$ yang artinya sebaran data adalah linear.

\section{Uji Hipotesis}

Untuk menguji hipotesis penelitian digunakan teknik analisis korelasi sederhana (Product Moment) dan teknik analisis korelasi ganda. Dalam penelitian ini ada tiga hipotesis yang diuji yaitu: 1) Diduga terdapat hubungan positif yang signifikan antara Mata Kuliah Tata Rias (X1) dengan Kewirausahaan Jasa MakeUp Artist (Y), 2) Diduga terdapat hubungan positif yang signifikan antara Mata Kuliah Tata Busana (X2) dengan Kewirausahaan Jasa MakeUp Artist (Y) dan 3) Diduga terdapat hubungan positif yang signifikan antara Mata Kuliah Tata Rias (X1) dan Tata Busana (X2) dengan Kewirausahaan Jasa MakeUp Artist (Y) Berikut disajikan perhitungan lebih lanjut.

a. Hubungan antara Mata Kuliah Tata Rias (X1) dengan Kewirausahaan Jasa MakeUp Artist (Y) Didapatkan hasil perhitungan korelasi sederhana dengan metode Product Moment menggunakan program SPSS sebagai berikut: nilai koefisien korelasi (r) antara Mata Kuliah Tata Rias dengan Kewirausahaan Jasa MakeUp Artist adalah 0,851 yang berarti masuk pada kategori derajat hubungan yang sangat tinggi. 
Nilai $r$ positif berarti hubungan Mata Kuliah Tata Rias dengan Kewirausahaan Jasa MakeUp Artist searah, dengan kata lain peningkatan Mata Kuliah Tata Rias akan diikuti peningkatan Kewirausahaan Jasa MakeUp Artist.

Selanjutnya diperoleh nilai $\mathrm{p}$ sebesar 0,00 yang artinya $\mathrm{p}$ lebih kecil dari 0,01 $(\mathrm{p}<0,01)$ maka antara Mata Kuliah Tata Rias dengan Kewirausahaan Jasa MakeUp Artist memiliki hubungan yang sangat signifikan.

Dengan demikian hipotesis yang menyatakan terdapat hubungan positif yang signifikan antara Mata Kuliah Tata Rias (X1) dengan Kewirausahaan Jasa MakeUp Artist (Y) dapat diterima.

b. Hubungan antara Mata Kuliah Tata Busana (X2) dengan Kewirausahaan Jasa MakeUp Artist (Y)

Didapatkan hasil perhitungan korelasi sederhana dengan metode Product Moment menggunakan program SPSS sebagai berikut: nilai koefisien korelasi (r) antara Mata Kuliah Tata Busana dengan Kewirausahaan Jasa Make Up Artist adalah 0,844 yang berarti masuk pada kategori derajat hubungan yang sangat tinggi. Nilai $r$ positif berarti hubungan Mata Kuliah Tata Busana dengan Kewirausahaan Jasa MakeUp Artist searah, dengan kata lain peningkatan Mata Kuliah Tata Busana akan diikuti peningkatan Kewirausahaan Jasa MakeUp Artist. Selanjutnya diperoleh nilai $\mathrm{p}$ sebesar 0,00 yang artinya $p$ lebih kecil dari 0,01 $(\mathrm{p}<0,01)$ maka antara Mata Kuliah Tata Busana (X2) dengan Kewirausahaan Jasa MakeUp
Artist (Y) memiliki hubungan yang sangat signifikan.

Dengan demikian hipotesis yang menyatakan terdapat hubungan positif yang signifikan antara Mata Kuliah Tata Busana (X2) dengan Kewirausahaan Jasa MakeUp Artist (Y) dapat diterima.

c. Hubungan antara Mata Kuliah Tata Rias (X1) dan Tata Busana (X2) dengan Kewirausahaan Jasa MakeUp Artist (Y)

Dari hasil pengolahan data berdasarkan sistem SPSS nilai koefisien korelasi (r) antara Mata Kuliah Tata Rias dan Tata Busana dengan Kewirausahaan Jasa MakeUp Artist adalah 0,898 yang berarti masuk pada kategori derajat hubungan yang sangat tinggi. Nilai $r$ positif berarti Mata Kuliah Tata Rias dan Tata Busana dengan Kewirausahaan Jasa MakeUp Artist searah, dengan kata lain peningkatan Mata Kuliah Tata Rias dan Tata Busana akan diikuti peningkatan Kewirausahaan Jasa MakeUp Artist.

Diperoleh nilai p sebesar 0,00 yang artinya $\mathrm{p}$ lebih kecil dari $0,01 \quad(\mathrm{p}<0,01)$ maka antara Mata Kuliah Tata Rias dan Tata Busana dengan Kewirausahaan Jasa MakeUp Artist memiliki hubungan yang sangat signifikan.

Diperoleh nilai $\mathrm{R}^{2}$ sebesar 0,807 yang artinya Mata Kuliah Tata Rias dan Tata Busana memberikan sumbangan efektif sebesar 80,7\% terhadap Kewirausahaan Jasa Make Up Artist.

Dengan demikian hipotesis yang menyatakan terdapat hubungan positif yang signifikan antara Mata Kuliah Tata Rias (X1) 
dan Tata Busana (X2) dengan Kewirausahaan Jasa MakeUp Artist (Y) dapat diterima.

\section{PENUTUP}

\section{Kesimpulan}

Berdasarkan hasil penelitian yang dilakukan, maka dapat ditarik kesimpulan sebagai berikut:

1. Terdapat hubungan positif yang signifikan antara Mata Kuliah Tata Rias (X1) dengan Kewirausahaan Jasa makeup Artist (Y), dibuktikan dengan nilai koefisien korelasi (r) sebesar 0,851 yang berarti masuk pada kategori derajat hubungan yang sangat tinggi. Nilai $r$ positif berarti hubungan Mata Kuliah Tata Rias dengan Kewirausahaan Jasa Make Up Artist searah. Diperoleh nilai p sebesar 0,00 $(\mathrm{p}<0,01)$ yang artinya antara Mata Kuliah Tata Rias dengan Kewirausahaan Jasa Make Up Artist memiliki hubungan yang sangat signifikan.

2. Hubungan positif yang signifikan antara Mata Kuliah Tata Busana (X2) dengan Kewirausahaan Jasa makeup Artist (Y) dibuktikan dengan nilai koefisien korelasi (r) sebesar 0,844 yang berarti masuk pada kategori derajat hubungan yang sangat tinggi. Nilai $r$ positif berarti hubungan Mata Kuliah Tata Busana dengan Kewirausahaan Jasa MakeUp Artist searah. diperoleh nilai $\mathrm{p}$ sebesar 0,00 $(\mathrm{p}<0,01)$ yang artinya antara Mata Kuliah Tata Busana (X2) dengan Kewirausahaan Jasa MakeUp Artist (Y) memiliki hubungan yang sangat signifikan.

3. Terdapat hubungan positif yang signifikan antara Mata Kuliah Tata Rias (X1) dan Tata
Busana (X2) dengan Kewirausahaan Jasa makeup Artist (Y)dibuktikan dengan nilai koefisien korelasi (r) sebesar adalah 0,898 yang berarti masuk pada kategori derajat hubungan yang sangat tinggi. Nilai $r$ positif berarti Mata Kuliah Tata Rias dan Tata Busana dengan Kewirausahaan Jasa MakeUp Artist searah. Diperoleh nilai $\mathrm{p}$ sebesar $0,00(\mathrm{p}<0,01)$ maka antara Mata Kuliah Tata Rias dan Tata Busana dengan Kewirausahaan Jasa MakeUp Artist memiliki hubungan yang sangat signifikan. Diperoleh nilai $\mathrm{R}^{2}$ sebesar 0,807 yang artinya Mata Kuliah Tata Rias dan Tata Busana memberikan sumbangan efektif sebesar 80,7\% terhadap Kewirausahaan Jasa MakeUp Artist.

\section{A. Saran}

1. Bagi Pihak Kampus dan Guru

a. Bagi Pihak Kampus

Supaya minat kewirausahan dari matakuliah tata rias dan busana meningkat, perlu ditambah jumlah sks mata kuliah tata rias dan busana, agar mahasiswa tidak harus terburu-buru dalam mempelajari matakuliah tata rias dan busana yang hanya memiliki 3 sks (dibagi 2), sehingga dalam melakukan praktek mahasiswa bisa lebih dalam mengusai materi.

b. Untuk Pihak Dosen

Dosen senantiasa menciptakan suasana yang menyenangkan dalam matakuliah tata rias dan busana.Agar mahasiswa tidajk merasa jenuh dalam belajar matakuliah tata rias dan busana.Hal ini dapat dilakukan dengan metode yang bervariasi dan berinovasi.Karena semakin tinggi motivasi belajar mahasiswa maka semakin besar peluang untuk menciptakan 
banyak wirausahawan sebelum dan setelah selesai kuliah.

\section{Bagi Penelitian Selanjutnya}

Penelitian ini memberikan informasi bahwa ada hubungan antara Matakuliah Tata Rias dan Busana dengan Kewirausahaan Jasa Make UpArtist pada Lulusan dan Mahasiswa Prodi Pendidikan Tari FBS Universitas Negeri Medan. Hasil tersebut menunjukkan bahwa kewirausahaan bisa saja dipengaruhi oleh variabel lain, diharapkan untuk peneltian selanjutnya untuk mengetahui matakuliah apasaja yang bisa berhubungan dengan kewirausahaan tersebut, selain yang diteliti oleh peneliti ini.

\section{DAFTAR PUSTAKA}

Arikunto, Suharsimi, 2006. Prosedur Penelitian : Suatu Pendekatan Praktek. (Edisi Revisi VI). Jakarta: Rineka Cipta

Budiyono, 2003. Metodologi Penelitian Pendidikan. Surakarta:UNS Press

.2004. Statistika untuk Penelitian.Surakarta:UNS Press

Caturwati, Endang, 1996. Rias dan Busana Tari Sunda. Bandung: STSI Press

Harymawan, 1993. Dramaturgi. Bandung: CV

Rosda Gay, 1982. Metode Penelitian Pendidikan. Jakarta: Bumi Aksara.

Hendro, 2011. Dasar - Dasar Kewirausahaan, Erlangga, Jakarta.

Jamal Ma'mur Asmani, 2011. Sekolah Entrepreneur. Yogyakarta: Harmoni.

Lupiyoadi, Rambat, 2014. Manajemen
Pemasaran Jasa, Jakarta: Salemba Empat

Mursyid, M, 1993. Manajmen Pemasaran. Jakarta: Bumi Aksara

Nana Syaodih S, 2007. Metode Penelitian Pendidikan. Bandung: PT. Remaja Rosdakarya Offset

Saiman, Leonardo, 2011. Kewirausahaan. Jakarta: Salemba Empat.

Soerjopranoto dan Poerwoesoenoe, 1994.Tata Rias Wajah Siang, Sore, Malam, Panggung dan Fantasi. Jakarta: Karya Utama

Sudjana, 2005. Metode Penelitian Kuantitatif dan Kualitatif. Jakarta: Salemba Empat

Sugiyono, 2007.Metode Penelitian Kuantitatif, Kualitatif dan $R \& D$, Bandung: Alfabeta

2009.Metode Penelitian Kuantitatif, Kualitatifdan $R \& D$, Bandung: Alfabeta

.2010. MetodePenelitian Pendidikan Pendekatan Kuantitatif, Kualitatif dan $R \& D$. Bandung: $\quad$ Alfabeta

_.2011. Metode Penelitian Kuantitatif Kualitatif dan $R \& D$. Bandung: Alfabeta

2012. Metode Penelitian Kuantitatif Kualitatif dan $R \& D$. Bandung: Alfabeta

.2015. Metode Penelitian Kuantitatif Kualitatif dan $R \& D$. Bandung: Alfabeta

Suharsimi Arikunto, 2006. Dasar-dasar Evaluasi Pendidikan. Jakarta: Rineka Cipta

Sukardi, 2005. Metodologi Penelitian Pendidikan (Kompetensi dan Praktiknya). Jakarta: Bumi Aksara. 
Supardi, 2013. Metodologi Penelitian Pendidikan Kuantitatif dan Kualitatif. Jakarta: Riuneka Cipta.

Supranto, 2004. Statistik Pasar Modal Keuangandan Perbankan, Jakarta: Rineka Cipta

Suryana, 2011. Kewirausahaan. Jakarta: Salemba Empat

Sutanto, 2014. Metode Penelitian Kuantitatif Kualitatif. Jakarta: Rineka Cipta

Tilaar, Martha. (1995), Indonesia Bersolek Tata Rias Kosmetik, Jakarta: 